\title{
Dietary habits and the presence and degree of asymptomatic diverticular disease by magnetic resonance imaging in a Western population: a population-based cohort study
}

\author{
Esther Askani', Susanne Rospleszcz ${ }^{2,3}$, Theresa Rothenbacher ${ }^{4}$, Nina Wawro ${ }^{5,6}$, Helmut Messmann', \\ Carlo N. De Cecco ${ }^{8}$, Ricarda von Krüchten ${ }^{1}$, Charlotte Kulka', Lena S. Kiefer ${ }^{4}$, Wolfgang Rathmann', \\ Annette Peters ${ }^{2,3,10}$, Christopher L. Schlett ${ }^{1}$, Fabian Bamberg ${ }^{1}$, Jakob Linseisen ${ }^{5,6}$ and Corinna Storz ${ }^{11^{*}}$ (D)
}

\begin{abstract}
Background: Despite the worldwide burden of diverticular disease, the connections between diverticular disease and dietary habits remain poorly understood, particularly in an asymptomatic representative sample. We investigated the association between asymptomatic diverticular disease as assessed by magnetic resonance imaging (MRI) and dietary habits in a Western study cohort.

Methods: Participants from a cross-sectional sample of a population-based cohort study underwent whole-body 3T-MRI including an isotropic VIBE-Dixon sequence. The presence and extent of diverticular disease was assessed in blinded fashion. Habitual dietary intake was recorded using a blended approach, applying 24-h food lists and a foodfrequency questionnaire. Traditional cardiometabolic risk factors were obtained by interviews and medical examination. Univariate and multivariate associations were calculated.

Results: A total of 308 subjects were included in this analysis ( $56 \%$ male, $56.4 \pm 9.1$ years). $39.9 \%$ had any form of diverticular disease and $15.3 \%$ had advanced asymptomatic diverticular disease. After adjustment for age, sex and total energy intake a higher intake of fiber and vegetables was associated with a lower odds for asymptomatic diverticular disease (fiber: OR 0.68 95\% Cl [0.48, 0.95]; vegetables: OR 0.72 95\% Cl [0.53, 0.97]) and an increased intake of meat was associated with an approximately two-fold higher odds for advanced asymptomatic diverticular disease (OR 1.84 95\% Cl $[1.13,2.99])$. However, after additional adjustment for body-mass-index (BMI), alcohol consumption, smoking behavior and physical activity only a high fiber and vegetables intake remained significantly associated with lower odds of asymptomatic diverticular disease.
\end{abstract}

Conclusion: Our results indicate that a high-fiber diet and increased intake of vegetables is associated with lower odds of having asymptomatic diverticular disease, independent of age, sex, total energy intake, BMI and other lifestyle factors.

Keywords: Diverticular disease, MRI, Dietary habits

\footnotetext{
*Correspondence: Corinna.Storz@uniklinik-freiburg.de

${ }^{11}$ Department of Neuroradiology, Medical Center - University

of Freiburg, Faculty of Medicine, University of Freiburg, Breisacher Str. 64, 79106 Freiburg, Germany

Full list of author information is available at the end of the article
}

\section{Background}

Diverticular disease is a common condition in Western countries with increasing prevalence [1-4]. Asymptomatic diverticular disease refers to the mere presence original author(s) and the source, provide a link to the Creative Commons licence, and indicate if changes were made. The images or other third party material in this article are included in the article's Creative Commons licence, unless indicated otherwise in a credit line to the material. If material is not included in the article's Creative Commons licence and your intended use is not permitted by statutory regulation or exceeds the permitted use, you will need to obtain permission directly from the copyright holder. To view a copy of this licence, visit http://creativecommons.org/licenses/by/4.0/. The Creative Commons Public Domain Dedication waiver (http://creativeco mmons.org/publicdomain/zero/1.0/) applies to the data made available in this article, unless otherwise stated in a credit line to the data. 
of diverticula, which are defined as small protrusions of colonic mucosa through the outer muscular layers at sites of vascular perforation [5]. Complications of diverticular disease resulting in clinically significant diverticulosis include diverticulitis, diverticular bleeding, perforation or obstruction [6-9]. Approximately $4-40 \%$ of patients with diverticular disease develop acute or chronic complications [10]. The estimated mortality rate due to diverticular disease and its complications amounts to 2.5 per 100,000 per year [11]. Furthermore diverticular disease is the fifth most important gastrointestinal disease in terms of healthcare costs in the United States [11]. Today, in industrialized western countries, approximately 5\% of people in their fifth decade and $50 \%$ of those in their ninth decade are affected with asymptomatic diverticular disease [3], indicating that the overall prevalence increases with age but also that its medical and economic relevance is likely to increase further as the population ages $[11,12]$.

Although little is known about the etiopathogenesis of diverticular disease [13], it has been observed that western and industrialized countries like the United States, Europe and Australia have a considerably higher prevalence of diverticular disease compared to countries such as Africa and Asia, which have prevalence rates of less than $0.5 \%$ [4]. This fact supports the consideration, that life-style factors may be responsible for the development of diverticular disease. Some risk factors have been identified unanimously by different studies to promote the development of diverticular disease whereas others are less understood and are still controversially discussed. Age, body mass index (BMI), waist circumference and waist-to-hip-ratio have been identified as risk factors for diverticular disease [14-18]. While there is evidence that the risk of diverticular disease was lower among vegetarians or vegans compared to meat eaters $[19,20]$, it was also observed that a high-fiber diet was associated with a higher prevalence of diverticula [16], whereas nut, corn and popcorn consumption did not increase the risk of diverticulosis or diverticular complications [21]. As such, despite the burden of diverticular disease the connections between diverticular disease and dietary habits remain poorly understood, particularly in an asymptomatic representative sample.

Previously we showed that magnetic resonance imaging (MRI) represents a valid, reproducible, non-invasive modality for the assessment of asymptomatic diverticular disease and our initial results confirmed that diverticular disease is common in a Western general population [22]. The objective of the present study was to determine the association of habitual dietary intake and the presence of asymptomatic diverticular disease as characterized by MRI in a sample of a general Western population. Our hypothesis was that a high-fiber diet and an increased intake of vegetables is associated with a lower degree of asymptomatic diverticular disease, whereas an increased meat intake is linked with a higher degree of asymptomatic diverticular disease.

\section{Methods \\ Study design and recruitment of participants}

This study was designed as a cross-sectional study, embedded in a population-based cohort from the 'Cooperative Health Research in the Augsburg Region, Germany' (KORA), as described elsewhere [23, 24].

KORA is a population-based research platform with subsequent follow-up studies in the fields of epidemiology, health economics, and health research. Within KORA, starting from 1996 four cross-sectional surveys S1 to S4 have been performed at five year interval, each comprising of an independent random sample, and serving as cohorts for long-term follow-up studies and as a pool for nested case-control and case-cohort studies [24].

The study population of the present study was recruited from the second follow-up of the KORA S4 cohort (FF4), which took place between June 2013 and September 2014 and comprises $\mathrm{N}=400$ participants from the FF4 study who were enrolled in an MRI substudy [23].

In brief, participants without prior cardiovascular disease underwent a whole-body MRI examination, if no contraindications to MRI and administration of gadolinium contrast were present. Participants with the following conditions were excluded from the study: $>72$ years of age, participants with prior cardiovascular diseases (e.g. stroke, myocardial infarction or revascularization), non-MRI-suitable implanted devices (e.g. cardiac pacemaker or implantable defibrillator, cerebral aneurysm clip, neural stimulator, any type of ear implant, ocular foreign body), pregnant or breast feeding participants, or participants with claustrophobia, known allergy against gadolinium compounds, or impaired renal function (serum creatinine $\geq 1,3 \mathrm{mg} / \mathrm{dl}$ ). All subjects underwent MRI within 3 months after their FF4 clinical examination [23].

\section{Nutrition and dietary habits}

Within the FF4 follow-up cohort of the KORA S4 health survey data on nutrition and dietary habits were collected until before the end of November 2014 [25]. Usual dietary intake was estimated with a blended approach combining repeated 24-h-food lists and a food frequency questionnaire (FFQ) [25]. Information about food consumption of the participants from up to three 24-h food lists [26] and a FFQ [27] were available to estimate consumption probabilities. We followed a two-step procedure, where the 
consumption probability and the amount of consumption on consumption days were estimated separately $[25$, $28]$. Both models included the same covariates, thereby linking the two parts. Consumption amounts on a consumption day were estimated based on the detailed food intake data collected in the Bavarian Food Consumption survey II [29]. The usual intake was then derived as the product of the probability of consuming a certain food and the usual amount consumed on a consumption day. Food intake data were aggregated to food groups and subgroups. Energy and nutrient intake data were calculated by linking the usual intake data to the German food composition database BLS, Version 3.02.

\section{Other covariates}

During the FF4 follow-up information on sociodemographic variables and lifestyle factors was collected in an extensive standardized face-to-face interview. Furthermore, all participants underwent anthropometric measurements [24].

BMI was defined as the value from the mass of the participant in kilogram divided by its height squares in meters and participants were categorized into (a) normal $\left(\mathrm{BMI}<25 \mathrm{~kg} / \mathrm{m}^{2}\right.$ ), (b) overweight (BMI 25 to $<30 \mathrm{~kg} / \mathrm{m}^{2}$ ) and (c) obese (BMI $\left.\geq 30 \mathrm{~kg} / \mathrm{m}^{2}\right)$, according to the definition of the world health organization [30].

Smoking behavior was defined as never-, ex- and current smoker (current regular or sporadic cigarette smoking) [31]. Alcohol consumption was assessed in g/d [32]. Physical activity was categorized as physically active (regular physical activity $\geq 1 \mathrm{~h} /$ week) or physically inactive (irregular physical activity $<1 \mathrm{~h} /$ week, almost no physical activity and no physical activity at all) $[31,33]$.

\section{Magnetic resonance imaging protocol and imaging analysis}

All participants underwent an identical imaging protocol on a 3 Tesla Magnetom Skyra (Siemens Healthineers, Erlangen, Germany), as detailed previously [23, 24].

\section{Assessment of diverticular disease}

For the assessment of asymptomatic diverticular disease, a two-point T1 weighted isotropic VIBE-Dixon gradient-echo sequence of the abdomen was employed (TR $4.06 \mathrm{~ms}$, TE 1.26, $2.49 \mathrm{~ms}$, flip angle $9^{\circ}$, partition thickness $1.7 \mathrm{~mm}$, isotropic in-plane resolution $1.7 \mathrm{~mm}$ ), as described previously $[22,23]$.

Diverticular disease was assessed in every colonic segment. The colonic segments were divided into the caecum, ascending colon, transverse colon, descending colon and sigmoid colon and screened for the assessment of diverticula by two independent and blinded readers [22]. A graded-scale system was used to classify the extent of colonic diverticula according to the number of diverticula [34]: grade $1=$ no diverticular disease, grade $2=$ mild diverticular disease with at least 1 but $<6$ diverticula in at least one colonic segment, grade $3=$ advanced diverticular disease with $\geq 6$ diverticula in at least one segment of the colon [22, 34].

\section{Statistical analysis}

Demographics, risk factors, and nutrition data of the participants are presented as arithmetic mean and standard deviation for continuous covariates and as counts and percentages for categorical covariates. Overall differences in these covariates between grades of diverticular disease were evaluated by ANOVA or $\chi^{2}$-Test, where appropriate. Differences in these covariates between participants with advanced diverticular disease and no diverticular disease were determined by $\mathrm{t}$-Test or $\chi^{2}$-Test. Associations of nutrition data to the presence of diverticular disease were assessed by logistic regression models adjusted for age, sex and total caloric energy intake in a Model 1 and additionally adjusted for BMI, physical activity, smoking behavior and alcohol consumption in a Model 2. As measures of association, odds ratios (OR) with corresponding 95\%-confidence intervals $(\mathrm{CI})$ were calculated per standard deviation of the variable of interest. All analyses were conducted with R v3.6.3 [35].

\section{Results}

Among 400 enrolled participants from the KORA study, 85 were excluded from the analysis due to missing information on dietary intake and 7 were excluded due to missing or not assessable imaging datasets (Fig. 1). In total, 308 participants ( $55.8 \%$ male, $56.4 \pm 9.1$ years) were eligible for the analysis of dietary habits and diverticular disease. Demographics of the study population are provided in Table 1. No difference was found between participants with and without available dietary intake data (Additional file 1: Table S1).

\section{Prevalence of diverticular disease based on MRI}

Overall, the prevalence of asymptomatic diverticular disease was high (prevalence: 123/308, 39.9\%) with the highest proportion categorized as mild diverticular disease $(24.7 \%)$ and $15.3 \%$ categorized as advanced diverticular disease.

\section{Association between habitual dietary intake and diverticular disease}

The mean intake of selected food groups, energy and nutrients per day in participants without and with asymptomatic diverticular disease according to the grade is detailed in Table 2. The mean energy intake of all 308 


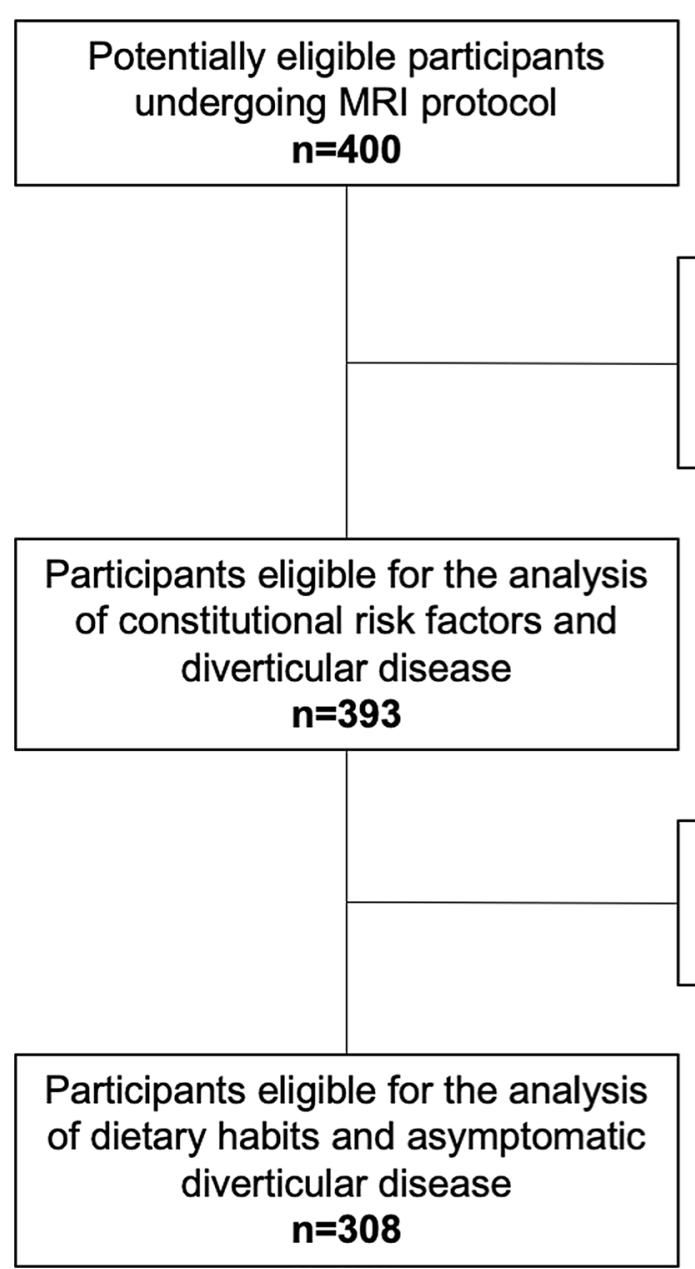

Fig. 1 Study flowchart of participant inclusion and exclusion

participants with information about dietary habits was $1836.5 \pm 409.3 \mathrm{kcal} /$ day.

In univariate analysis, subjects with any form of asymptomatic diverticular disease had significantly lower mean vegetable intake compared to subjects without diverticular disease $(173.2 \pm 66.8$ vs. $159.1 \pm 49.4$ vs. $147.9 \pm 43.1 \mathrm{~g} /$ day in participants without vs. mild vs. advanced diverticular disease respectively; all $p<0.05$; Table 2). While participants without diverticular disease showed the highest mean fiber intake per day $(16.8 \pm 4.7 \mathrm{~g} /$ day $)$, participants with advanced diverticular disease showed a higher fiber intake than participants with mild diverticular disease ( $16.2 \pm 3.6$ vs. $15.7 \pm 3.8 \mathrm{~g} /$ day in participants with advanced vs. mild diverticular disease; Table 2).

While participants with advanced diverticular disease showed the highest mean intake of meat or meat products per day ( $129.5 \pm 41.5 \mathrm{~g} /$ day), participants without diverticular disease showed a higher meat intake compared to participants with mild diverticular disease (122.5 \pm 44.4 vs. $115.2 \pm 38.3 \mathrm{~g} /$ day in participants without vs. mild diverticular disease; Table 2).

After adjustment for age, sex and total energy intake, a higher intake of fiber and vegetables was associated with a lower odds for any form of asymptomatic diverticular disease (OR 0.68, 95\% CI [0.48, 0.95]; $p=0.022$ and OR $0.72,95 \%$ CI $[0.53,0.97] ; p=0.030$ for fiber and vegetable intake respectively; Table 3), whereas high intake of meat and meat products was associated with an approximately two-fold higher odds ratio for advanced diverticular disease (OR 1.84, 95\% CI [1.13, 2.99]; $p=0.014$; Table 3). After additional adjustment for BMI, smoking behavior, alcohol consumption and physical activity only a highfiber intake and higher intake of vegetables remained significantly associated with lower odds of asymptomatic diverticular disease (OR 0.64, 95\% CI [0.44, 0.94]; $p=0.024$ and OR $0.66,95 \%$ CI $[0.47,0.94] ; p=0,023$ for fiber and vegetable intake respectively Table 3 ). Age 
Table 1 Participants' demographic and risk factors by grade of asymptomatic diverticular disease

\begin{tabular}{|c|c|c|c|c|c|c|}
\hline & All & No diverticular disease & Mild diverticular disease & $\begin{array}{l}\text { Advanced } \\
\text { diverticular } \\
\text { disease }\end{array}$ & $p$ value (all) & $\begin{array}{l}p \text { value advanced versus } \\
\text { no diverticular disease }\end{array}$ \\
\hline & $\mathrm{N}=308$ & $N=185(60.1 \%)$ & $N=76(24.7 \%)$ & $\mathrm{N}=47(15.3 \%)$ & & \\
\hline Age (years) & $56.4 \pm 9.1$ & $54.5 \pm 8.7$ & $57.0 \pm 9.2$ & $62.9 \pm 7.2$ & $<0.001$ & $<0.001$ \\
\hline Men & $172(55.8 \%)$ & $102(55.1 \%)$ & $40(52.6 \%)$ & $30(63.8 \%)$ & 0.456 & 0.726 \\
\hline $\mathrm{BMI}\left(\mathrm{kg} / \mathrm{m}^{2}\right)$ & $28.0 \pm 5.0$ & $27.6 \pm 5.0$ & $27.4 \pm 4.3$ & $30.5 \pm 5.3$ & 0.001 & 0.001 \\
\hline Normal & 89 (28.9\%) & $56(30.3 \%)$ & $25(32.9 \%)$ & $8(17.0 \%)$ & 0.004 & 0.007 \\
\hline Overweight & $127(41.2 \%)$ & $78(42.2 \%)$ & $35(46.1 \%)$ & $14(29.8 \%)$ & & \\
\hline Obese & $92(29.9 \%)$ & $51(27.6 \%)$ & $16(21.1 \%)$ & $25(53.2 \%)$ & & \\
\hline Alcohol (g/d) & $18.2 \pm 23.9$ & $17.8 \pm 24.9$ & $18.5 \pm 23.0$ & $19.7 \pm 21.2$ & 0.879 & 0.623 \\
\hline Physical activity & & & & & & \\
\hline Inactive & $122(39.6 \%)$ & $72(38.9 \%)$ & $32(42.1 \%)$ & $18(38.3 \%)$ & 0.874 & 1.000 \\
\hline Active & $186(60.4 \%)$ & $113(61.1 \%)$ & $44(57.9 \%)$ & $29(61.7 \%)$ & & \\
\hline Smoking & & & & & & \\
\hline Never-smoker & $114(37.0 \%)$ & $72(38.9 \%)$ & $26(34.2 \%)$ & $16(34.0 \%)$ & 0.568 & 0.279 \\
\hline Ex-smoker & $135(43.8 \%)$ & $76(41.1 \%)$ & $34(44.7 \%)$ & $25(53.2 \%)$ & & \\
\hline Smoker & $59(19.2 \%)$ & $37(20.0 \%)$ & $16(21.1 \%)$ & $6(12.8 \%)$ & & \\
\hline Total cholesterol (mg/dl) & $217.4 \pm 36.3$ & $212.9 \pm 34.9$ & $222.1 \pm 39.1$ & $227.7 \pm 35.0$ & 0.019 & 0.025 \\
\hline HDL cholesterol (mg/dl) & $62.5 \pm 17.8$ & $63.0 \pm 17.7$ & $63.7 \pm 19.2$ & $58.2 \pm 15.3$ & 0.199 & 0.196 \\
\hline LDL cholesterol (mg(dl) & $139.2 \pm 33.5$ & $133.9 \pm 33.5$ & $143.8 \pm 33.3$ & $152.6 \pm 29.8$ & 0.001 & 0.001 \\
\hline Triglycerides (mg/dl) & $128.2 \pm 79.7$ & $126.9 \pm 88.7$ & $120.7 \pm 67.4$ & $145.2 \pm 55.6$ & 0.240 & 0.321 \\
\hline Vitamin D (ng/ml) & $23.1 \pm 11.4$ & $22.2 \pm 11.5$ & $24.8 \pm 11.3$ & $24.2 \pm 10.8$ & 0.196 & 0.557 \\
\hline $\begin{array}{l}\text { Systolic blood pressure } \\
(\mathrm{mmHg})\end{array}$ & $120.0 \pm 16.4$ & $117.6 \pm 15.6$ & $120.5 \pm 17.6$ & $128.9 \pm 14.6$ & $<0.001$ & $<0.001$ \\
\hline $\begin{array}{l}\text { Diastolic blood pressure } \\
(\mathrm{mmHg})\end{array}$ & $74.8 \pm 10.0$ & $74.6 \pm 9.3$ & $73.8 \pm 11.3$ & $77.5 \pm 10.0$ & 0.111 & 0.143 \\
\hline $\begin{array}{l}\text { Antihypertensive medica- } \\
\text { tion }\end{array}$ & $84(27.3 \%)$ & $34(18.4 \%)$ & $24(31.6 \%)$ & $26(55.3 \%)$ & $<0.001$ & $<0.001$ \\
\hline Antithrombotic drugs & 20 (6.5\%) & $4(2.2 \%)$ & $11(14.5 \%)$ & $5(10.6 \%)$ & $<0.001$ & 0.037 \\
\hline
\end{tabular}

Bold values denote statistical significance at the $p<0.05$ level

Variables as mean and standard deviation or number and percentage. $p$ values from t-test or $\mathrm{X}^{2}$-test, where appropriate. $\mathrm{BMI}=$ body mass index, $\mathrm{HDL}=\mathrm{high}$-density lipoprotein, $\mathrm{LDL}=$ low-density lipoprotein

Table 2 Mean intake of selected food/nutrients per day in participants without and with asymptomatic diverticular disease according to grade

\begin{tabular}{lcccccc}
\hline & All & No diverticular disease & Mild diverticular disease & $\begin{array}{l}\text { Advanced } \\
\text { diverticular } \\
\text { disease }\end{array}$ & $\begin{array}{l}\boldsymbol{p} \text { value } \\
\text { (no vs. } \\
\text { mild) }\end{array}$ & $\begin{array}{l}\boldsymbol{p} \text { value (no } \\
\text { vs. advanced) }\end{array}$ \\
& & & & $1850.0 \pm 343.6$ & 0.266 & 1 \\
\hline $\begin{array}{l}\text { Total energy intake (kilocalories) } \\
\text { (kcal/d) }\end{array}$ & $1836.5 \pm 409.3$ & $1860.2 \pm 438.9$ & $1770.4 \pm 367.1$ & $129.5 \pm 41.5$ & 0.182 & 0.625 \\
Meat, meat products (g/d) & $121.7 \pm 42.6$ & $122.5 \pm 44.4$ & $115.2 \pm 38.3$ & $21.0 \pm 10.6$ & 0.830 & 1 \\
Fish, crustaceans (g/d) & $22.2 \pm 14.7$ & $22.5 \pm 14.7$ & $22.3 \pm 17.0$ & $61.2 \pm 17.4$ & 0.155 & 0.219 \\
Potatoes, tubers (g/d) & $56.6 \pm 18.9$ & $56.2 \pm 19.3$ & $54.5 \pm 18.7$ & $147.9 \pm 43.1$ & $\mathbf{0 . 0 1 9}$ & $\mathbf{0 . 0 2 0}$ \\
Vegetables (g/d) & $165.9 \pm 60.3$ & $173.2 \pm 66.8$ & $159.1 \pm 49.4$ & $149.0 \pm 71.0$ & 0.461 & 1 \\
Fruits, nuts (g/d) & $146.2 \pm 73.8$ & $149.2 \pm 78.8$ & $137.0 \pm 62.2$ & $174.1 \pm 107.0$ & 0.358 & 0.576 \\
Milk, dairy products (g/d) & $185.2 \pm 103.2$ & $192.1 \pm 104.6$ & $175.3 \pm 97.2$ & $163.6 \pm 34.0$ & 0.173 & 0.816 \\
Grain, cereal products (g/d) & $166.1 \pm 45.6$ & $169.8 \pm 48.1$ & $158.4 \pm 44.9$ & $70.3 \pm 12.6$ & 0.233 & 1 \\
Protein (g/d) & $69.9 \pm 14.8$ & $70.8 \pm 15.8$ & $67.4 \pm 13.5$ & $77.3 \pm 14.8$ & 0.278 & 1 \\
Fat (g/d) & $77.0 \pm 16.4$ & $78.0 \pm 17.5$ & $74.5 \pm 14.2$ & $16.2 \pm 3.6$ & 0.129 & 0.688 \\
Fiber (g/d) & $16.4 \pm 4.4$ & $16.8 \pm 4.7$ & $15.7 \pm 3.8$ & & \\
\hline
\end{tabular}

Bold values denote statistical significance at the $p<0.05$ level

Variables as mean and standard deviation. $p$ values from t-test with Bonferroni correction 
Table 3 Multiple regression analysis of association of dietary intake to presence of asymptomatic diverticular disease

\begin{tabular}{|c|c|c|c|c|c|c|c|c|c|c|c|c|}
\hline & \multicolumn{6}{|c|}{$\begin{array}{l}\text { Model } 1 \\
\text { (adjusted for age, sex, and total energy intake) }\end{array}$} & \multicolumn{6}{|c|}{$\begin{array}{l}\text { Model } 2 \\
\text { (Model } 1 \text { + adjusted for BMI, alcohol consumption, } \\
\text { smoking behavior and physical activity) }\end{array}$} \\
\hline & \multicolumn{3}{|c|}{$\begin{array}{l}\text { Outcome no versus any } \\
\text { diverticular disease }\end{array}$} & \multicolumn{3}{|c|}{$\begin{array}{l}\text { Outcome no versus } \\
\text { advanced diverticular } \\
\text { disease }\end{array}$} & \multicolumn{3}{|c|}{$\begin{array}{l}\text { Outcome no versus any } \\
\text { diverticular disease }\end{array}$} & \multicolumn{3}{|c|}{$\begin{array}{l}\text { Outcome no versus } \\
\text { advanced diverticular } \\
\text { disease }\end{array}$} \\
\hline & OR & $95 \% \mathrm{Cl}$ & $p$ & OR & $95 \% \mathrm{Cl}$ & $p$ & OR & $95 \% \mathrm{Cl}$ & $p$ & OR & $95 \% \mathrm{Cl}$ & $p$ \\
\hline \multicolumn{13}{|l|}{ Dietary intake } \\
\hline Meat, meat products & 1.18 & {$[0.84,1.65]$} & 0.335 & 1.84 & {$[1.13,2.99]$} & 0.014 & 1.07 & {$[0.71,1.6]$} & 0.759 & 1.40 & {$[0.77,2.54]$} & 0.268 \\
\hline Vegetables & 0.72 & {$[0.53,0.97]$} & 0.030 & 0.60 & {$[0.37,0.99]$} & 0.045 & 0.66 & {$[0.47,0.94]$} & 0.023 & 0.53 & {$[0.29,0.97]$} & 0.041 \\
\hline Fruits, nuts & 0.78 & {$[0.6,1.02]$} & 0.072 & 0.74 & {$[0.5,1.1]$} & 0.139 & 0.77 & {$[0.58,1.01]$} & 0.060 & 0.70 & {$[0.46,1.06]$} & 0.093 \\
\hline Fiber & 0.68 & {$[0.48,0.95]$} & 0.022 & 0.57 & {$[0.34,0.94]$} & 0.028 & 0.64 & {$[0.44,0.94]$} & 0.024 & 0.59 & {$[0.33,1.05]$} & 0.074 \\
\hline
\end{tabular}

Bold values denote statistical significance at the $p<0.05$ level

Presented are odds ratios (OR) and 95\% confidence intervals (CI) from a logistic regression model with outcome diverticular disease. Models are adjusted for age, sex, total energy intake, BMI, alcohol consumption and smoking behavior. All predictor variables were standardized $($ mean $=0, S D=1)$ before analysis

was significantly associated with lower meat consumption $(\beta=-0.63,95 \%$ CI $[-1.06,-0.20], p=0.004)$ after adjustment for total energy intake, while the presence of asymptomatic diverticular disease increased with age.

\section{Discussion}

We investigated the association of habitual dietary intake with the presence and extent of asymptomatic diverticular disease as characterized by MRI in a sample of a general Western population. We found that high intake of vegetables and fiber was associated with a lower prevalence of asymptomatic diverticular disease, independent of age, sex, total energy intake, BMI and lifestyle factors such as smoking behavior, alcohol consumption and physical activity. Furthermore, we found that an increased intake of meat or meat products was associated with an approximately two-fold higher odds for the prevalence of advanced diverticular disease, independent of age, sex and total energy intake, however, after additional adjustment for BMI and lifestyle factors this association attenuated. Moreover, high intake of fruits and nuts had no impact on presence or extent of asymptomatic diverticular disease. Thus, our study contributes to the evidence that there is an association between dietary intake and the presence of diverticular disease with protective effects of high-fiber diet and increased intake of vegetables.

It is still a controversy, if a low-fiber diet promotes the development of diverticular disease and its complications. So far, findings have been conflicting, as Peery et al. $[16,36]$ refuted the assumption of a relationship between diverticulosis and a low-fiber diet and even found that a high-fiber diet was associated with higher, rather than lower prevalence of diverticulosis, while Crowe et al. reported a protective effect of a high-fiber diet versus diverticular disease in the prospective follow-up EPIC Oxford study [19]. One possible explanation may include selection bias, as Peery et al. [36] enrolled subjects with at least one histologically verified resected adenoma prior study entry. Also, one of his studies was nested in larger studies assessing environmental and life-style factors associated with colorectal adenomas in patients undergoing an outpatient colonoscopy [16]. However, our findings are in line with Crowe et al. We investigated fiber intake in an asymptomatic cohort with no complications of diverticular disease, while Crowe et al. [19] studied the links between fiber intake and the development of complications of diverticular disease. Consequently, our results indicate that a low-fiber diet not only plays an important role in the development of complications of diverticular disease, but also in the development of diverticula.

Previously, Painter and Burkitt [2] introduced the hypothesis that a low-fiber diet was responsible for development of diverticular disease, because a low-fiber diet would cause excessive colonic pressure resulting in herniation of the mucosa through the muscle wall. In our study, we found that the presence of asymptomatic diverticular disease was significantly associated with a lowfiber diet, independent of the risk factors age, sex, total energy intake, BMI and lifestyle factors (smoking behavior, alcohol consumption and physical activity). Interestingly, we observed, that mean fiber intake was lower in participants with mild diverticular disease as compared to participants with advanced diverticular disease. Thus, one could speculate that low-fiber intake earlier in life may have contributed to the development of diverticular disease, while high-fiber intake later in life-and perhaps 
detected by our study-may not have a healing effect on the condition anymore. Given our detected inverse association between fiber intake and asymptomatic diverticular disease, early dietary intervention and education may be beneficial in preventing progression of the disease.

We found that an intake of vegetables was significantly inversely associated with asymptomatic diverticular disease in univariate analysis as well as after adjustment for age, sex, total energy intake, BMI and lifestyle factors (smoking behavior, alcohol consumption and physical activity).

While there have been studies, which found a lower risk of diverticular disease and its complications in vegetarian participants $[19,37]$, our study investigates the implications of a low vegetable intake on the presence of diverticular disease independently of a vegetarian lifestyle. Thus, our results may allow the assumption that a high amount of consumed vegetables may prevent the development of diverticular disease independently from other dietary habits.

Specifically, rapid bowel transit times and increased frequency of bowel movements is considered to be the possible biological mechanism through which a vegetarian and high-fiber diet lowers the risk of diverticular disease $[38,39]$. A reduced transit time leads to less water being reabsorbed in the lower gastrointestinal tract resulting in larger soft stools that are easier to pass and consequently a lower intraluminal pressure and a reduced likelihood of forming diverticula [5]. The fact, that the risk of diverticular disease was found to be lower in vegetarian participants $[19,37]$, is in line with our findings, as an increased intake of meat or meat products was linked with an approximately two-fold increased odds of advanced diverticular disease independent of age, sex and total energy intake.

Contrary to the assumptions of previous studies, we found no association of diverticular disease with the intake of grains, fruits and nuts, confirming the findings of a prospective follow-up study of US men of Strate et al. [21], who rebuted the general presumption of a negative effect of grains, nuts and popcorn in the development of diverticular disease or diverticular complications.

Even though other lifestyle factors such as alcohol consumption, smoking and physical inactivity have been described as risk factors for diverticular disease [40, 41], we did not detect a significant association with the presence and extent of diverticular disease in univariate analysis, as previously reported [22]. However, as these factors have been described as risk factors for diverticular disease, we considered these confounders in our multiple regression analysis.

It has already been observed that age is an important risk factor for diverticular disease [3] and consistently, we previously found an association between the presence and extent of diverticular disease and higher age [22]. Notably, our findings on impact of nutrition findings persisted after adjustment for age, supporting earlier nutritional research, which has shown that diets do not change greatly over time and for many people recent diet is a reasonable reflection of diet several years or decades previously [42].

This study has potential limitations. Overall, we included 308 participants, which represents not the entire sample of the initially enrolled subjects. However, while this may have induced a potential selection bias, subjects were only excluded due to incomplete scanning protocols or insufficient image quality and no significant demographic difference was observed. The initial study design focused on the assessment of subclinical cardiovascular alterations in a Western study population, thus, the participants did not receive specific bowel preparation and the extent of diverticula in the colonic segments could have been underestimated. Data on possible symptomatic or complicated disease were not specifically collected and outcome data on the development of inflammatory alterations or complicative diverticular disease were also missing. However, no participant showed imaging indications of complicative diverticular disease. Also, the survey methodology for the assessment of habitual dietary intake only refers to a limited time period. Thus, our dietary data do not describe long-term diet and validity of general nutrition details and details about dietary habits are limited. Furthermore, longitudinal outcome data is missing, as this study represents the baseline cross-sectional study results. Hence, further large-scale studies are warranted to validate the generalizability of our findings.

\section{Conclusions}

In conclusion, our results indicate that a high-fiber diet and an increased intake of vegetables is linked to a lower risk of asymptomatic diverticular disease, independent of age, sex, total energy intake, BMI, smoking behavior, alcohol consumption and physical activity. Furthermore, an increased intake of meat or meat products is positively associated with the occurrence of advanced diverticular disease, while an increased intake of fruits and nuts is not associated with the presence and extent of diverticular disease. Given the significant health burden of diverticular disease and its complications and the lack of reliable studies about risk factors for asymptomatic diverticular disease, our findings may contribute to a better understanding of the underlying pathomechanisms and this may have high relevance for risk stratification and the establishment of preventive measures. 


\section{Abbreviations}

BMI: Body mass index; Cl: Confidence interval; FFQ: Food frequency questionnaire; KORA: Cooperative Health Research in the Augsburg Region, Germany; MRI: Magnetic resonance imaging; OR: Odds ratio.

\section{Supplementary Information}

The online version contains supplementary material available at https://doi. org/10.1186/s12986-021-00599-4.

Additional file 1. Table S1. Comparison of the participants without available nutrition data to those with available nutrition data.

\section{Acknowledgements}

Not applicable.

\section{Authors' contributions}

Study concept and design were performed by EA, SR, FB, AP, JL and CS. Acquisition, analysis, or interpretation of data was performed by EA, SR, JL and CS. Drafting of the manuscript was performed by EA, SR and CS. Critical revision of the manuscript for important intellectual content was performed by EA, SR, TR, NW, HM, CNC, RK, CK, LSK, WR, AP, CLS, FB, JL and CS. Statistical analysis was performed by SR. Administrative, technical, or material support was performed by EA, CS, AP, JL and FB. All authors read and approved the final manuscript.

\section{Funding}

Open Access funding enabled and organized by Projekt DEAL. This study was funded by the German Research Foundation (DFG, Bonn, Germany), the German Center for Cardiovascular Disease Research (DZHK, Berlin, Germany) and the German Center for Diabetes Research (DZD e.V., Neuherberg, Germany). The KORA study was initiated and financed by the Helmholtz Zentrum München-German Research Center for Environmental Health, which was funded by the German Federal Ministry of Education and Research (BMBF) and by the State of Bavaria.

\section{Availability of data and material}

The datasets used and/or analyzed during the current study are available from the corresponding author on reasonable request.

\section{Declarations}

\section{Ethics approval and consent to participate}

The KORA study was approved by the Institutional Research Ethics Board of the medical faculty of Ludwig-Maximilian University Munich, Germany and compiled with the Helsinki declaration on human research. All participants provided written informed consent.

\section{Consent for publication}

All participants authorized the use of data in this study.

\section{Competing interests}

The authors declare that they have no competing interests.

\section{Author details}

${ }^{1}$ Department of Diagnostic and Interventional Radiology, Medical Center University of Freiburg, Freiburg, Germany. ${ }^{2}$ Chair of Epidemiology, Institute for Medical Information Processing, Biometry, and Epidemiology, LudwigMaximilians-University Munich, Munich, Germany. ${ }^{3}$ Institute of Epidemiology, Helmholtz Center Munich, German Research Center for Environmental Health, Neuherberg, Germany. ${ }^{4}$ Department of Diagnostic and Interventional Radiology, University Hospital Tuebingen, Tuebingen, Germany. ${ }^{5}$ Independent Research Group Clinical Epidemiology, Helmholtz Center Munich, German Research Center for Environmental Health, Neuherberg, Germany. ${ }^{6}$ Chair of Epidemiology, Ludwig-Maximilians University of Munich, UNIKA-T Augsburg, Augsburg, Germany. ${ }^{7}$ Department of Internal Medicine III, Klinikum Augsburg, Augsburg, Germany. ${ }^{8}$ Division of Cardiothoracic Imaging, Department of Radiology and Imaging Sciences, Emory University Hospital, Atlanta, GA, USA. ${ }^{9}$ Institute of Biometrics and Epidemiology, German Diabetes Center,
Duesseldorf, Germany. ${ }^{10}$ German Center for Cardiovascular Disease Research (DZHK E.V.), Munich, Germany. ${ }^{11}$ Department of Neuroradiology, Medical Center - University of Freiburg, Faculty of Medicine, University of Freiburg, Breisacher Str. 64, 79106 Freiburg, Germany.

Received: 17 February 2021 Accepted: 3 July 2021

Published online: 16 July 2021

\section{References}

1. Everhart JE, Ruhl CE. Burden of digestive diseases in the United States part II: lower gastrointestinal diseases. Gastroenterology. 2009;136(3):741-54

2. Painter NS, Burkitt DP. Diverticular disease of the colon: a deficiency disease of Western civilization. Br Med J. 1971;2(5759):450-4.

3. Petruzziello L, lacopini F, Bulajic M, Shah S, Costamagna G. Review article: uncomplicated diverticular disease of the colon. Aliment Pharmacol Ther. 2006;23(10):1379-91.

4. Warner E, Crighton EJ, Moineddin R, Mamdani M, Upshur R. Fourteenyear study of hospital admissions for diverticular disease in Ontario. Can J Gastroenterol. 2007;21(2):97-9.

5. Stollman N, Raskin JB. Diverticular disease of the colon. Lancet. 2004:363(9409):631-9.

6. Parks TG. Natural history of diverticular disease of the colon. Clin Gastroenterol. 1975;4(1):53-69.

7. Horner JL. Natural history of diverticulosis of the colon. Am J Dig Dis. 1958:3(5):343-50.

8. Jacobs DO. Clinical practice. Diverticulitis N Engl J Med. 2007;357(20):2057-66.

9. Peery AF, Dellon ES, Lund J, Crockett SD, McGowan CE, Bulsiewicz WJ, et al. Burden of gastrointestinal disease in the United States: 2012 update. Gastroenterology. 2012;143(5):1179-87.

10. Shahedi K, Fuller G, Bolus R, Cohen E, Vu M, Shah R, et al. Long-term risk of acute diverticulitis among patients with incidental diverticulosis found during colonoscopy. Clin Gastroenterol Hepatol. 2013;11(12):1609-13.

11. Sandler RS, Everhart JE, Donowitz M, Adams E, Cronin K, Goodman C, et al. The burden of selected digestive diseases in the United States. Gastroenterology. 2002;122(5):1500-11.

12. Shaheen NJ, Hansen RA, Morgan DR, Gangarosa LM, Ringel Y, Thiny MT, et al. The burden of gastrointestinal and liver diseases, 2006. Am J Gastroenterol. 2006;101(9):2128-38.

13. Strate LL, Modi R, Cohen E, Spiegel BM. Diverticular disease as a chronic illness: evolving epidemiologic and clinical insights. Am J Gastroenterol. 2012;107(10):1486-93.

14. Koehler R. The incidence of colonic diverticulosis in Finland and Sweden. Acta Chir Scand. 1963;126:148-55.

15. Debray C, Hardouin JP, Besancon F, Raimbault J. [Incidence of colic diverticulosis according to age. Statistical study from 500 barium enemas]. Sem Hop. 1961;37:1743-5.

16. Peery AF, Barrett PR, Park D, Rogers AJ, Galanko JA, Martin CF, et al. A high-fiber diet does not protect against asymptomatic diverticulosis. Gastroenterology. 2012;142(2):266-72.

17. Peery AF, Keku TO, Martin CF, Eluri S, Runge T, Galanko JA, et al. Distribution and characteristics of colonic diverticula in a United States screening population. Clin Gastroenterol Hepatol. 2016;14(7):980-5.

18. Strate LL, Liu YL, Aldoori WH, Syngal S, Giovannucci EL. Obesity increases the risks of diverticulitis and diverticular bleeding. Gastroenterology. 2009;136(1):115-22

19. Crowe FL, Appleby PN, Allen NE, Key TJ. Diet and risk of diverticular disease in Oxford cohort of European Prospective Investigation into Cancer and Nutrition (EPIC): prospective study of British vegetarians and non-vegetarians. BMJ. 2011;343:d4131.

20. Cao Y, Strate LL, Keeley BR, Tam I, Wu K, Giovannucci EL, et al. Meat intake and risk of diverticulitis among men. Gut. 2018;67(3):466-72.

21. Strate LL, Liu YL, Syngal S, Aldoori WH, Giovannucci EL. Nut, corn, and popcorn consumption and the incidence of diverticular disease. JAMA. 2008;300(8):907-14.

22. Storz C, Rothenbacher T, Rospleszcz S, Linseisen J, Messmann H, De Cecco CN, et al. Characteristics and associated risk factors of diverticular 
disease assessed by magnetic resonance imaging in subjects from a Western general population. Eur Radiol. 2019;29(3):1094-103.

23. Bamberg F, Hetterich H, Rospleszcz S, Lorbeer R, Auweter SD, Schlett $\mathrm{CL}$, et al. Subclinical disease burden as assessed by whole-body MRI in subjects with prediabetes, subjects with diabetes, and normal control subjects from the general population: the KORA-MRI study. Diabetes. 2017;66(1):158-69.

24. Holle R, Happich M, Lowel H, Wichmann HE, Group MKS. KORA—a research platform for population based health research. Gesundheitswesen. 2005;67(Suppl 1):S19-25.

25. Mitry P, Wawro N, Six-Merker J, Zoller D, Jourdan C, Meisinger C, et al. Usual dietary intake estimation based on a combination of repeated $24-\mathrm{H}$ food lists and a food frequency questionnaire in the KORA FF4 crosssectional study. Front Nutr. 2019;6:145.

26. Freese J, Feller S, Harttig U, Kleiser C, Linseisen J, Fischer B, et al. Development and evaluation of a short 24-h food list as part of a blended dietary assessment strategy in large-scale cohort studies. Eur J Clin Nutr. 2014:68(3):324-9.

27. Bohlscheid-Thomas S, Hoting I, Boeing H, Wahrendorf J. Reproducibility and relative validity of food group intake in a food frequency questionnaire developed for the German part of the EPIC project. European Prospective Investigation into Cancer and Nutrition. Int J Epidemiol. 1997;26(Suppl 1):S59-70

28. Tooze JA, Midthune D, Dodd KW, Freedman LS, Krebs-Smith SM, Subar AF, et al. A new statistical method for estimating the usual intake of episodically consumed foods with application to their distribution. J Am Diet Assoc. 2006:106(10):1575-87.

29. Wawro N, Kleiser C, Himmerich S, Gedrich K, Boeing H, Knueppel S, et al. Estimating usual intake in the 2nd Bavarian food consumption survey: comparison of the results derived by the national cancer institute method and a basic individual means approach. Ann Nutr Metab. 2017;71(3-4):164-74.

30. Purnell JQ. Definitions, Classification, and Epidemiology of Obesity. In: Feingold KR, Anawalt B, Boyce A, Chrousos G, Dungan K, Grossman A, et al., editors. Endotext. South Dartmouth (MA) 2000.

31. Rabel M, Laxy M, Thorand B, Peters A, Schwettmann L, Mess F. Clustering of health-related behavior patterns and demographics. Results from the population-based KORA S4/F4 cohort study. Front Public Health. 2018;6:387.
32. Ruf E, Baumert J, Meisinger C, Döring A, Ladwig KH. Are psychosocial stressors associated with the relationship of alcohol consumption and all-cause mortality? BMC Public Health. 2014;14:312.

33. Bertheau RC, Lorbeer R, Nattenmüller J, Wintermeyer E, Machann J, Linkohr $\mathrm{B}$, et al. Bone marrow fat fraction assessment in regard to physical activity: KORA FF4-3-T MR imaging in a population-based cohort. Eur Radiol. 2020;30(6):3417-28.

34. De Cecco CN, Ciolina M, Annibale B, Rengo M, Bellini D, Muscogiuri G, et al. Prevalence and distribution of colonic diverticula assessed with CT colonography (CTC). Eur Radiol. 2016;26(3):639-45.

35. R Core Team. R: A language and environment for statistical computing. $R$ Foundation Statistical Computing, Vienna, Austria. 2020.

36. Peery AF, Sandler RS, Ahnen DJ, Galanko JA, Holm AN, Shaukat A, et al. Constipation and a low-fiber diet are not associated with diverticulosis. Clin Gastroenterol Hepatol. 2013;11(12):1622-7.

37. Gear JS, Ware A, Fursdon P, Mann JI, Nolan DJ, Brodribb AJ, et al. Symptomless diverticular disease and intake of dietary fibre. Lancet. 1979:1(8115):511-4.

38. Gear JS, Brodribb AJ, Ware A, Mann Jl. Fibre and bowel transit times. Br J Nutr. 1981:45(1):77-82.

39. Sanjoaquin MA, Appleby PN, Spencer EA, Key TJ. Nutrition and lifestyle in relation to bowel movement frequency: a cross-sectional study of 20630 men and women in EPIC-Oxford. Public Health Nutr. 2004;7(1):77-83.

40. Nagata N, Niikura R, Shimbo T, Kishida Y, Sekine K, Tanaka S, et al. Alcohol and smoking affect risk of uncomplicated colonic diverticulosis in Japan. PLOS ONE. 2013;8(12):e81137.

41. Williams PT. Incident diverticular disease is inversely related to vigorous physical activity. Med Sci Sports Exerc. 2009;41 (5):1042-7.

42. Dunn JE, Liu K, Greenland P, Hilner JE, Jacobs DR Jr. Seven-year tracking of dietary factors in young adults: the CARDIA study. Am J Prev Med. 2000;18(1):38-45.

\section{Publisher's Note}

Springer Nature remains neutral with regard to jurisdictional claims in published maps and institutional affiliations.
Ready to submit your research? Choose BMC and benefit from:

- fast, convenient online submission

- thorough peer review by experienced researchers in your field

- rapid publication on acceptance

- support for research data, including large and complex data types

- gold Open Access which fosters wider collaboration and increased citations

- maximum visibility for your research: over 100M website views per year

At BMC, research is always in progress.

Learn more biomedcentral.com/submissions 